American Journal of Pharmacology and Toxicology 5 (2): 119-124, 2010

ISSN 1557-4962

(C) 2010 Science Publications

\title{
The Intracerebroventricular Administration of W-7, A Calmodulin Inhibitor, Attenuate the Development of Morphine Tolerance in Rats
}

\author{
${ }^{1}$ Gholamreza Sepehri, ${ }^{1}$ Vahid Sheibani, ${ }^{2}$ Afrooz Azarang, ${ }^{3}$ Ali Shamsizadeh, \\ ${ }^{1}$ Mohammad Reza Afarinesh, ${ }^{1}$ Saeed Azizollahi and ${ }^{4}$ Ehsan Sepehri \\ ${ }^{1}$ Neuroscience Research Center, \\ ${ }^{2}$ Physiology Research Center, \\ Kerman University of Medical Sciences, Kerman, Iran \\ ${ }^{3}$ Department of Physiology, Rafsanjan University of Medical Sciences, Rafsanjan, Iran \\ ${ }^{4}$ Tehran University of Medical Sciences, Tehran, Iran
}

\begin{abstract}
Problem statement: The present study was performed to determine the effect of Intracerebroventricular (ICV) administration of W-7, a specific calmodulin inhibitor, on the analgesic effect and development of tolerance to antinociceptive effect of acute and chronic morphine administration respectively. Approach: This study was carried out on male wistar rats, weighing 200-250 g. For acute experimental protocol, Morphine was injected intraperitonealy in a single dose $\left(5 \mathrm{mg} \mathrm{kg}^{-1}\right)$. For chronic experimental protocol, Morphine was administered daily (15 $\mathrm{mg} \mathrm{kg}^{-1}$ for 8 days). The threshold to thermal nociceptive stimuli was measured by tail-flick test. In acute and chronic experiments, W-7 $(0.25,0.5$ and $1 \mu \mathrm{mol} / \mathrm{rat})$ was injected through ICV at different paradigms. Maximal Possible Effect percentage (MPE\%) was considered as analgesia index. Results: Our result showed that W-7 $(0.25,0.5$ and $1 \mu \mathrm{mol} / \mathrm{rat})$ injections before acute morphine administration significantly reduced the analgesic effect of morphine compared with morphine treated group (all $\mathrm{p}<0.05$ ). Chronic morphine exposure induced tolerance to its antinociceptive effect and administration of W-7 ( 0.5 and $1 \mu \mathrm{mol} / \mathrm{rat}$ ) decreased the development of tolerance to it. Conclusion: In conclusion these data showed that acute administration of W-7 reduced the analgesics effect of morphine and chronic injection of W-7 inhibited the development of morphine tolerance which indicates that calmodulin and its dependent pathways may play a role in the morphine tolerance processes.
\end{abstract}

Key words: Calmodulin inhibitor (W-7), morphine, tolerance, tail-flick test, pain, rat

\section{INTRODUCTION}

Tolerance is indicated by a decreased efficacy of the drug after chronic use, leading to the requirement for a higher dose to get the desired effect (Hamdy et al., 2004). Accumulating evidences have revealed that prolong exposure to opiates such as morphine and heroin can significantly alter brain function, leading to the development of tolerance to opiates (Eisch et al., 2000; Kelley et al., 2000; Nestler and Aghajanian, 1997). However, the underlying central mechanisms for opiate tolerance are not entirely understood.

Calcium ions are thought to play an important role in many cellular processes. Interaction of calcium with several calcium-binding proteins, the main one of which, Calmodulin (Gnegy, 1993), is a critical step for activating or deactivating of different cellular pathways such as enzyme activation, plasma $\mathrm{Ca}^{2+}$ pump regulation and protein phosphorylation and dephosphorylation cascades (Cheung, 1982; Dinsmore and Sloboda, 1988; Ye et al., 2004). A number of studies indicate that opioid tolerance is associated with alteration in the calcium homeostasis and free intracellular $\mathrm{Ca}^{2+}$ concentration is higher in the brain (Diaz et al., 1995; Welch and Olson, 1991). Increased in cytosolic calcium concentration activate several intracellular enzymes including protein kinases (Wroblewski and Danysz, 1989). Protein kinases such as $\mathrm{Ca}^{2+} /$ Calmodulin-dependent protein Kinases (CaMK) have been reported to phosphorylate opioid receptor, leading to receptor desensitization (Koch et al., 1997; Mestek et al., 1995); a phenomenon which plays a

Corresponding Author: Gholamreza Sepehri, Neuroscience Research Center, Kerman University of Medical Sciences, Kerman, Iran Tel: +98- 341- 2264196 Fax: +98- 341- 2264198 
critical role in opioid tolerance (Breivogel et al., 1997; Yabaluri and Medzihradsky, 1997). If this were to be the case, an essential process for opioid receptor phosphorylation and desensitization could be the activation of the $\mathrm{Ca}^{2+} /$ calmodulin complex. A previous report which described the inhibition of morphine tolerance by intraventricular application of CaMK II inhibitor favors this possibility (Tang et al., 2006). However, the effect of specific calmodulin inhibitors such as W-7 on the antinociceptive effect and tolerance to morphine is not determined yet. So the major aim of the present study was to study the effect of supraspinal inhibition of calmodulin by its specific inhibitor, W-7, on the analgesic effects and development of tolerance to morphine in male rats.

\section{MATERIALS AND METHODS}

Animals: Male Wistar rats, weighing 200-250 g were used in this study. Subjects were housed four per cage in a temperature-controlled room at $25 \pm 1^{\circ} \mathrm{C}$ on $12: 12 \mathrm{~h}$ light-dark cycle with lights on at 07:00 am. The experiments were carried out during the light phase of the cycle. The animals had free access to commercial food for rodents (Teklad Rodent Diet, Iran) and drinking water. Rats were divided randomly into several experimental groups, each comprising 7-9 animals. All of the procedures were in accordance with guidelines for caring and using of laboratory animals in Neuroscience Research Center of Kerman University of Medical Sciences and the European Communities Council Directive of 24 November 1986 (86/609/EEC).

Drugs: Morphine hydrochloride (Temad Co, Iran) was dissolved in saline. W-7 (N-(6-aminohexyl)-5-chloro-1naphtalenesulfonamide) was purchased from Alexis Company; USA and was dissolved in 100\% DMSO as vehicle (Dimethyl Sulfoxide, Merck Company, Germany).

Surgical procedure: Each rat was anaesthetized by an intraperitoneal injection (i.p) of $60 \mathrm{mg} \mathrm{kg}^{-1}$ ketamine and $5 \mathrm{mg} \mathrm{kg}^{-1}$ xylazine. They were then placed in the stereotaxic instrument (Stoelting Company, USA). A single incision was made on the midline of the scalp. Once the area had been prepped, a stainless steel 21 gauge cannula was placed in the lateral ventricle according to the Paxinos and Watson (1986) atlas. The coordinates were $1.0 \mathrm{~mm}$ posterior to the bregma and $1.5 \mathrm{~mm}$ lateral of the midline and $3.0 \mathrm{~mm}$ inferior of the duramater. The cannula was kept in place on the skull by dental cement and bone screws. The rats were allowed a 7days recovery period after the surgery for implantation of the cannula. The injections were done, using a 23 gauge stainless steel cannula attached to polyethylene tubing and $10 \mu \mathrm{L}$ Hamilton syringe (Hamilton Inc., Reno, NV).

After the completion of experiments, the animals were sacrificed by an overdosage of ketamine and xylazine combination and then dye was injected through the cannulas to mark the ventricular space. The brain sections were visually examined to verify that the tip of the cannula was located in the lateral cerebral ventricle.

Tail-flick test: Antinociception was assessed by tailflick test. Radiant heat was applied at $5-8 \mathrm{~cm}$ from the tip of the tail using a tail-flick apparatus (PANLAB 7160, Spain). Tail Flick Latency (TFL) was measured as the time of the beam exposure to the withdrawal time of the tail. The mean of three consecutive TFL was measured at $1 \mathrm{~min}$ intervals before drug or solvent administration (basal latency) and then similar TFL was measured at specific times after drug or solvent administration, (experimental latencies) (Mahani et al., 2005a). The intensity of radiant heat was adjusted to establish the basal latency of 3-5 sec. To avoid tissue damage, a cut-off time of $15 \mathrm{sec}$ was set. Trials were automatically terminated if a response did not occur within $15 \mathrm{sec}$ (Doi et al., 1988). Maximal Possible Effect percentage (MPE\%) was considered as analgesia index which was calculated by the following formula:

$$
\mathrm{MPE} \%=\frac{\text { Experimental latency-basal latency }}{15-\text { basal latency }} \times 100
$$

Effect of W-7 on morphine-induced analgesia: All rats underwent surgical procedure and a cannula was placed in the lateral ventricle of rats' brain. The animals were tested 7 days after Cannulation. On the experimental day, a single dose of morphine $\left(5 \mathrm{mg} \mathrm{kg}^{-1}\right)$ was administered intraperitonealy. In control group, saline was injected i.p. Tail-Flick Latency (TFL) was measured before and 30, 60, 90 and $120 \mathrm{~min}$ after morphine administration (Mahani et al., 2005b). In experimental groups, $\mathrm{W}-7(0.25,0.5$ and $1 \mu \mathrm{mol} / \mathrm{rat})$ was injected ICV $10 \mathrm{~min}$ before the intraperitoneal administration of morphine. DMSO (vehicle) was administered ICV in the same schedule as control group. All of ICV injections were performed with a micro injector in an amount of $10 \mu \mathrm{L}$ at a constant rate within $1 \mathrm{~min}$. 


\section{Experimental groups:}

1. Rats that received a single dose of morphine (5 $\mathrm{mg} \mathrm{kg}^{-1} /$ i.p) and DMSO Intracerebroventricularly (ICV)

2. Rats that received saline intraperitoneally and DMSO was injected by ICV

3. Rats that received maximum dose of $\mathrm{W}-7$ $(1 \mu \mathrm{mol} / \mathrm{rat} / \mathrm{ICV}) 10 \mathrm{~min}$ before intraperitoneal saline injection

4-6. Experimental treated rats that received W-7 (0.25, 0.5 and $1 \mu \mathrm{mol} / \mathrm{rat} / \mathrm{ICV}) 10 \mathrm{~min}$ before morphine (5 $\mathrm{mg} \mathrm{kg}^{-1} /$ i.p) injection

Morphine tolerance: All rats underwent surgical procedure and were tested 7 days after cannulation. Tolerance to morphine was induced by daily morphine injections (15 mg kg$/ 1 /$ i.p) for 8 days. Tail-Flick Latency (TFL) was measured both before and $30 \mathrm{~min}$ after morphine administration in days $1,3,5$ and 8 (Mahani et al., 2005a). W-7 (0.25, 0.5 and $1 \mu \mathrm{mol} / \mathrm{rat})$ was administered Intracerebroventricularly (ICV) 10 min before morphine administration but in days that tail-flick test was performed (1,3,5 and 8), W-7 was injected after doing the tail-flick test. All of ICV injections were performed with a micro injector in an amount of $10 \mu \mathrm{L}$ at a constant rate within $1 \mathrm{~min}$.

\section{Experimental group:}

1. Rats that received morphine $\left(15 \mathrm{mg} \mathrm{kg}^{-1} /\right.$ i.p) for 8 days

2. Rats that received saline i.p for 8 days

3. Rats that received saline i.p and DMSO Intracerebroventricularly (ICV) for 8 days

4. Rats that received morphine ( $15 \mathrm{mg} \mathrm{kg}^{-1} /$ i.p) and DMSO (ICV) for 8 days

5. Rats that received saline i.p and maximum dose of $\mathrm{W}-7$ ( $1 \mu \mathrm{mol} / \mathrm{rat} / \mathrm{ICV})$ for 8 days

6-8. Experimental treated rats that received ICV injection of W-7 $(0.25,0.5$ and $1 \mu \mathrm{mol} / \mathrm{rat})$ and morphine ( $15 \mathrm{mg} \mathrm{kg}^{-1} /$ i.p) for 8 days

Statistical analysis: The results are expressed as mean \pm SEM of at least 6 rats in each group. The difference in MPE\% (antinociception) between groups over the time course of study was determined by two-way Analysis Of Variance (ANOVA), followed by the Tukey post hoc test with 5\% level of significance $(\mathrm{p}<0.05)$. For accessing tail flick latencies or MPE\% in one group for several days we used repeated measure test. One sample t-test was used to determine the cause of difference and Bonferroni adjustment was used for reducing error.

\section{RESULTS}

Effect of ICV injection of W-7 on morphine-induced analgesia: We first tested whether supraspinal inhibition of calmodulin activity by its specific inhibitor (W-7), interfere with the analgesic effect of morphine. $\mathrm{W}-7(0.25,0.5$ and $1 \mu \mathrm{mol} / \mathrm{rat})$ or its vehicle (DMSO) was injected ICV $10 \mathrm{~min}$ before the intraperitoneal administration of a single dose of morphine $\left(5 \mathrm{mg} \mathrm{kg}^{-1}\right)$. Tail-flick test was performed before and 30, 60, 90 and $120 \mathrm{~min}$ after morphine administration. Following morphine administration, an analgesic response (about 70\% MPE) produced since $30 \mathrm{~min}$ and lasted for about $120 \mathrm{~min}$. Administration of W-7 ( $1 \mu \mathrm{mol} / \mathrm{rat})$ by itself produced slight antinociceptive effect (18.5\% MPE). However, the injection of W-7 at $0.25,0.5$ or $1 \mu \mathrm{mol} / \mathrm{rat}$ prior to morphine administration caused a decrease in the peak response to morphine to nearly $40 \% \mathrm{MPE}$ which is significantly lower than morphine treated group $(\mathrm{p}<0.05)$. The analgesic effect of $\mathrm{W}-7+$ morphine also last shorter (about $90 \mathrm{~min}$ ) than that of DMSO + morphine-treated group (about $120 \mathrm{~min}$ ) (Fig. 1).

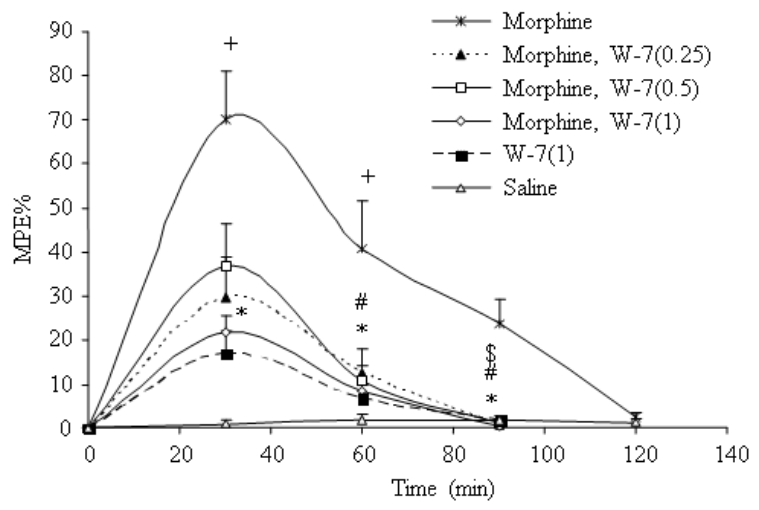

Fig. 1: The effect of ICV injection of W-7 $(0.25,0.5$ and $1 \mu \mathrm{mol} / \mathrm{rat}$ ) on the antinociceptive effect of morphine $(5 \mathrm{mg} \mathrm{kg} / \mathrm{i} . \mathrm{p})$ in rats. W-7 was injected $10 \mathrm{~min}$ prior to morphine injection and tail flick response was measured before and 30, 60, 90 and 120 min after morphine administration. W-7 and DMSO were injected intracerebroventricularly and morphine and saline were injected intraperitonealy. Values represent mean \pm SEM of at least 6 rats in each group. (+) $\mathrm{p}<0.05$ compared to Saline and W-7 treated groups; $(*) \quad \mathrm{p}<0.05$ Morphine+W-7 (1 $\mu \mathrm{mol} / \mathrm{rat}$ ) with Morphine; (\#) $\mathrm{p}<0.05$ Morphine+W-7 (0.5) with Morphine at 60 and 90 min; (\$) $\mathrm{p}<0.05$ Morphine compared to W-7 treated groups 
Am. J. Pharm. \& Toxicol., 5 (2): 119-124, 2010

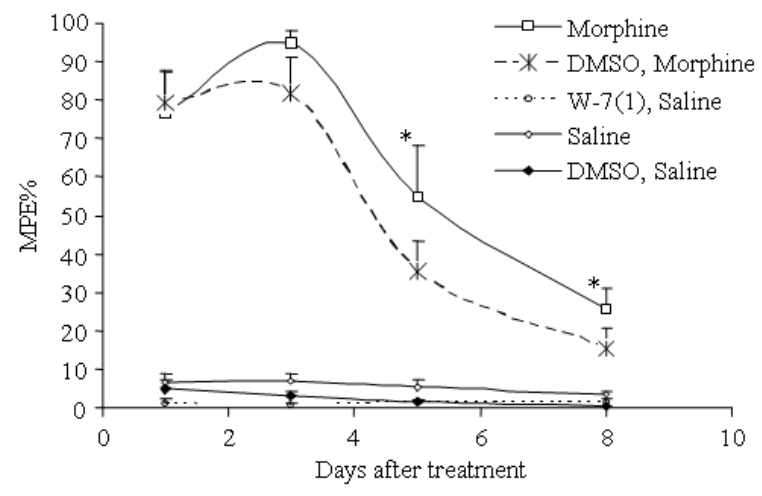

Fig. 2: Tolerance to analgesic effects of morphine induced by chronic morphine administration. Morphine $\left(15 \mathrm{mg} \mathrm{kg}^{-1} / \mathrm{i} . \mathrm{p}\right)$ administered for 8 days. W-7 and DMSO were injected intracerebroventricularly, $10 \mathrm{~min}$ prior to saline or morphine injection except on days which tail flick test performed. Tail flick response was measured before and $30 \mathrm{~min}$ after morphine administration on days $1,3,5$ and 8 . Values represent mean \pm SEM of at least 6 rats in each group. Chronic morphine administration (15 $\mathrm{mg} \mathrm{kg}^{-1} 8$ days $^{-1} /$ i.p) induced tolerance to its antinociceptive effect; MPE\% on the fifth and eighth days were significantly reduced compared with MPE\% on the first day, in the morphine group and $\mathrm{DMSO}+$ morphine group $(\mathrm{p}<0.05)$. ICV injection of $\mathrm{W}-7 \quad(1 \mu \mathrm{mol} / \mathrm{rat})$ with i.p administration of saline did not affect MPE \% compared with saline- treated group $(\mathrm{p}>0.05)$

Effect of ICV injection of W-7 on the development of tolerance to analgesic effect of morphine: In the second part of the experiment, we examined whether chronic supraspinal inhibition of calmodulin by W-7 could affect the development of morphine tolerance. As it is shown in Fig. 2, chronic administration of morphine alone for 8 days induced tolerance to its antinociceptive effect; the MPE\% on day 5(45\%) and day $8(30 \%)$ was significantly reduced compared with MPE\% on the first day (80\%) in this group (all $\mathrm{p}<0.05$ ). The tolerance to the analgesic effect of morphine treatment alone was not significantly different from that of DMSO + morphine - treated group. ICV injection of $\mathrm{W}-7(1 \mu \mathrm{mol} / \mathrm{rat})$ with i.p administration of saline did not affect the Maximal Possible Effect percentage (MPE\%) compared with saline- treated group (p>0.05) (Fig. 2).

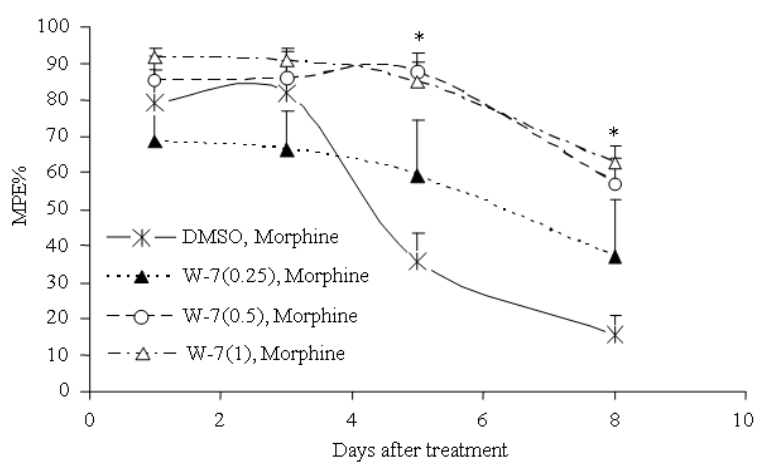

Fig. 3: The effect of ICV administration of W-7 (0.25, 0.5 and $1 \mu \mathrm{mol} / \mathrm{rat}$ ) on the development of tolerance to analgesic effect of morphine (15 mg kg 8 days $^{-1} /$ i.p) in rats. Other notations are the same as in Fig. 2. (*) p $<0.05$ W-7 (1 $\mu \mathrm{mol} / \mathrm{rat})+$ Morphine and $\mathrm{W}-7$ $(0.5 \mu \mathrm{mol} / \mathrm{rat})+$ morphine as compared to morphine + DMSO-treated rats

The MPE on day 8 in morphine + W-7 $(0.25$ micromol/rat) group was about $35 \%$ which slightly increased in comparison with morphine + W-7 Vehicletreated rats. However, this increase was not statistically significant ( $p>0.05$ ). However, MPE\% on day 5 and 8 in rats receiving morphine $+\mathrm{W}-7$ ( $0.5 \mathrm{micromol} / \mathrm{rat})$ was about 90 and $62 \%$ respectively which showed a significant increase in morphine analgesic response compared with that of morphine + DMSO-treated rats (both $\mathrm{p}<0.05$ ). MPE\% on 5th and 8th day in group treated with morphine $+\mathrm{W}-7(1 \mu \mathrm{mol} / \mathrm{rat})$ was 85 and $65 \%$ which significantly increased in comparison with rats treated with morphine + DMSO $(\mathrm{p}<0.05)$. In fact, MPE\% on day 5 and 8 in rats receiving W-7 (0.5 and $1 \mu \mathrm{mol} / \mathrm{rat}$ ) did not show any significant difference as compared with MPE\% on first day in their own groups. It means that chronic ICV administration of $\mathrm{W}-7$ in dose 0.5 and $1 \mu \mathrm{mol} / \mathrm{rat}$ could effectively inhibited the development of morphine tolerance (Fig. 3).

\section{DISCUSSION}

The present study was designed to evaluate the effect of acute and chronic calmodulin inhibition by microinjection of its specific inhibitor "W-7" into the lateral ventricle of the rat's brain on the analgesic effect and development of morphine tolerance. Our results showed that acute ICV administration of $\mathrm{W}-7$ before morphine injection inhibited analgesic effects of morphine. Our results are consistent with recent studies indicating that calmodulin is involved in $G$ protein signal pathway initiated by $\mathrm{G}$ protein-coupled receptors 
such as opioid receptors (Ye et al., 2004; Wang et al., 1999). Wang et al. (1999) has been shown that calmodulin interact directly with the mu opioid receptor at the third intracellular loop and may play as an independent second messenger molecule that is released upon receptor stimulation. Also, it is reported that morphine increases $\mathrm{CaM}$ contents in mouse brain (Niu et al., 2000). Therefore, it seems logic that inhibition of calmodulin activity could attenuate the analgesic effects of morphine. Our result showed that in vivo administration of calmodulin inhibitor could inhibit the morphine analgesic effects and support our hypnosis.

In addition, we found that chronic ICV administration of W-7 strongly attenuated the development of tolerance to chronic morphine exposure, as evidenced by a significant increased in the Maximal Possible Effect (MPE \%) on day 5 and 8 in comparison with morphine $+\mathrm{W}-7$ Vehicle-treated group.

Since on days that we measured the antinociceptive effect of morphine, W-7 was injected after performing tail-flick test, it is unlikely that the inhibition of morphine tolerance by $\mathrm{W}-7$ was due to the acute interaction between $\mathrm{W}-7$ and morphine.

It has been shown that calmodulin content and location changed during chronic morphine administration. It is reported that chronic morphine treatment increased calmodulin contents in the rat's brain (Nehmad et al., 1982). Moreover, the intracellular calcium elevation by opioid receptor stimulation (Diaz, et al., 1995; Welch and Olson, 1991) leads to calmodulin dissociation from cell membrane (Wang et al., 1999). The increase in cytosolic calmodulin prompts the translocation of calmodulin into the nucleus (Wang et al., 2000) which regulates the gene expression by morphine (Niu et al., 2000; Deisseroth et al., 1998). However, it is unclear whether these finding may play a role in the development of morphine tolerance or not.

In addition, several lines of evidence indicated that calmodulin dependent pathways such as $\mathrm{Ca}^{2+} /$ Calmodulin Kinase II (CaMKII) activation may involve in the morphine tolerance (Liang et al., 2004). It has been reported that intraventricular application of CaMK II inhibitor attenuated morphine tolerance (Tang et al., 2006). However, an important characteristic of CaMK II is its autophosphorylation which enables this kinase to phosphorylate substrates in a $\mathrm{Ca}^{2+} /$ calmodulin-independent manner and thus prolongs the duration of its effect (Lou et al., 1999). Our results showed that in rat, administration of calmodulin inhibitor, W-7 inhibited the development of morphine tolerance. So, it could be possible that calmodulin activity is important in the mechanisms underlying morphine tolerance.

\section{CONCLUSION}

In summary, our results indicated that chronic inhibition of calmodulin activity by ICV injection of its specific inhibitor, W-7, attenuated morphine tolerance but acute W-7 administration decreased the antinociceptive effects of morphine. Further studies need to be carried out to better understand the underlying mechanism (s) of these findings and determine the relevance of them in human.

\section{ACKNOWLEDGMENT}

This study was supported by Neuroscience Research Center, Kerman University of Medical Sciences, Kerman, Iran.

\section{REFERENCES}

Breivogel, C.S., D.E. Selley and S.R. Childers, 1997. Acute and chronic effects of opioids on $\delta$ and $\mu$ receptor activation of $\mathrm{G}$ proteins in NG108-15 and SK-N-SH cell membranes. J. Neurochem., 68: $1462-1472$. DOI: $10.1046 / j .1471-$ 4159.1997.68041462.x

Cheung, W.Y., 1982. Calmodulin: An overview. Fed. Proc., 41: 2253-2257. PMID: 6281080

Deisseroth, K., E.K. Heist and R.W. Tsien, 1998. Translocation of calmodulin to the nucleus supports CREB phosphorylation in hippocampal neurons. Nature, 392: 198-202. DOI: 10.1038/32448

Diaz, A., F. Ruiz, J. Florez, A. Pazos and M.A. Hurle, 1995. Regulation of dihydropyridine-sensitive $\mathrm{Ca}++$ channels during opioid tolerance and supersensitivity in rats. J. Pharmacol. Exp. Ther., 274: 1538-1544. PMID: 7562531

Dinsmore, J.H. and R.D. Sloboda, 1988. Calcium and calmodulin-dependent phosphorylation of a $62 \mathrm{kd}$ protein induces microtubule depolymerization in sea urchin mitotic apparatuses. Cell, 53: 769-780. DOI: 10.1016/0092-8674(88)90094-3

Doi, T., S. Kuzuna and M. Fujino, 1988. Study on the receptor subtypes mediating the analgesic action of an enkephalin analog, Tyr-D-Met(O)-Gly-EtPheNHNHCOCH3.AcOH (EK-399). Jap. J. Pharmacol., 47: 409-415. DOI: 10.1254/jjp.47.409

Eisch, A.J., M. Barrot, C.A. Schad, D.W. Self and E.J. Nestler, 2000. Opiates inhibit neurogenesis in the adult rat hippocampus. Proc. Natl. Acad. Sci., 97: 7579-7584. PMID: 10840056 
Gnegy, M.E., 1993. Calmodulin in neurotransmitter and hormone action. Annu. Rev. Pharmacol. Toxicol., 33: 45-70. DOI: 10.1146/annurev.pa.33.040193.000401

Hamdy, M.M., Y. Noda, M. Miyazaki, T. Mamiya and A. Nozaki et al., 2004. Molecular mechanisms in dizocilpine-induced attenuation of development of morphine dependence: An association with cortical $\mathrm{Ca}^{2+} /$ calmodulin-dependent signal cascade. Behav. Brain Res., 152: 263-270. DOI: 10.1016/j.bbr.2003.10.014

Kelley, A.E., V.P. Bakshi, S. Fleming and M.R. Holahan, 2000. A pharmacological analysis of the substrates underlying conditioned feeding induced by repeated opioid stimulation of the nucleus accumbens. Neuropsychopharmacology, 23: 455-467. PMID: 10989273

Koch, T., T. Kroslak, P. Mayer, E. Raulf and V. Hollt, 1997. Site mutation in the rat $\mu$-opioid receptor demonstrates the involvement of calcium/calmodulin-dependent protein kinase II in agonist-mediated desensitization. J. Neurochem., 69: $1767-1770$. DOI: $10.1046 / \mathrm{j} .1471-$ 4159.1997.69041767.x

Liang, D., X. Li and J.D. Clark, 2004. Increased expression of $\mathrm{Ca}^{2+} /$ calmodulin-dependent protein kinase II alpha during chronic morphine exposure. Neuroscience, 123: 769-775. DOI: 10.1016/j.neuroscience.2003.10.007

Lou, L., T. Zhou, P. Wang and G. Pei, 1999. Modulation of $\mathrm{Ca}^{2+} /$ calmodulin-dependent protein kinase II activity by acute and chronic morphine administration in rat hippocampus: Differential regulation of alpha and beta isoforms. Mol. Pharmacol., 55: 557-563. PMID: 10051541

Mahani, S.E., F. Motamedi, M. Javan and A. Ahmadiani, 2005a. Involvement of hypothalamic pituitary adrenal axis on the effects of nifedipine in the development of morphine tolerance in rats. Pharmacol. Biochem. Behav., 81: 152-157. DOI: 10.1016/j.pbb.2005.03.004

Mahani, S.E., S. Vahedi, F. Motamedi, A. Pourshanazari and M. Khaksari et al., 2005b. Nifedipine potentiates antinociceptive effects of morphine in rats by decreasing hypothalamic pituitary adrenal axis activity. Pharmacol. Biochem. Behav., 82: 17-23. DOI: 10.1016/j.pbb.2005.07.006

Mestek, A., J.H. Hurley, L.S. Bye, A.D. Campbell and Y. Chen et al., 1995. The human mu opioid receptor: Modulation of functional desensitization by calcium/calmodulin-dependent protein kinase and protein kinase C. J. Neurosci., 15: 2396-2406. PMID: 7891175
Nehmad, R., H. Nadler and R. Simantov, 1982. Effects of acute and chronic morphine treatment of calmodulin activity of rat brain. Mol. Pharmacol., 22: 389-394. PMID: 6128669

Nestler, E.J. and G.K. Aghajanian, 1997. Molecular and cellular basis of addiction. Science, 278: 58-63. DOI: $10.1126 /$ science.278.5335.58

Niu, S., C.H. Kuo, Y. Gan, E. Nishikawa and T. Sadakata et al., 2000. Increase of calmodulin III gene expression by $\mu$-opioid receptor stimulation in PC12 cells. Jap. J. Pharmacol., 84: 412-417. DOI: 10.1254/jjp.84.412

Paxinos, G. and C. Watson, 1986. The Rat Brain: In Stereotaxic Coordinates. 2nd Edn., Academic Press, Sydney, ISBN: 0125476213, pp: 264.

Tang, L., P.K. Shukla, L.X. Wang and Z.J. Wang, 2006. Reversal of morphine antinociceptive tolerance and dependence by the acute supraspinal inhibition of $\mathrm{Ca}^{2+} /$ calmodulin-dependent protein kinase II. J. Pharmacol. Exp. Ther., 317: 901-909. DOI: 10.1124/jpet.105.097733

Wang, D., L.M. Tolbert, K.W. Carlson and W. Sadee, 2000. Nuclear $\mathrm{Ca}^{2+} /$ calmodulin translocation activated by $\mu$-opioid $\left(\mathrm{OP}_{3}\right)$ receptor. J. Neurochem., 74: 1418-1425. DOI: 10.1046/j.14714159.2000.0741418.x

Wang, D., W. Sadee and J.M. Quillan, 1999. Calmodulin binding to $\mathrm{G}$ protein-coupling domain of opioid receptors. J. Biol. Chem., 274: 22081-22088. DOI: $10.1074 /$ jbc.274.31.22081

Welch, S.P. and K.G. Olson, 1991. Opiate toleranceinduced modulation of free intracellular calcium in synaptosomes. Life Sci., 48: 1853-1861. PMID: 1710309

Wroblewski, J.T. and W. Danysz, 1989. Modulation of glutamate receptors: Molecular mechanisms and functional implications. Annu. Rev. Pharmacol. Toxicol., 29: 441-474. DOI: 10.1146/annurev.pa.29.040189.002301

Yabaluri, N. and F. Medzihradsky, 1997. Downregulation of mu-opioid receptor by full but not partial agonists is independent of $G$ protein coupling. Mol. Pharmacol., 52: 896-902. PMID: 9351981

Ye, X.F., Y. Lu, P. Zhang and J.H. Liang, 2004. Calmodulin inhibitor trifluoperazine attenuates the development and expression of morphine-induced conditioned place preference in rats. Eur. J. Pharmacol., 486: 265-271. DOI: 10.1016/j.ejphar.2004.01.002 